\title{
O MODO DE VIDA DEMOCRÁTICO E SUA RESPONSABILIDADE SOCIAL PERANTE OS DIREITOS HUMANOS
}

\author{
Rita Pimenta ${ }^{1}$ \\ Universidade Federal do Juiz de Fora, Brasil \\ ritapimentar@yahoo.com.br \\ Alexandre Campelo \\ Universidade Federal do Piauí, Brasil \\ campeloalexandre@yahoo.com.br
}

\begin{abstract}
RESUMO: O presente ensaio objetiva discutir a relação entre a democracia compreendida como um modo de vida e os direitos humanos. Encontra-se neste texto um inventário de algumas das principais premissas que explicam o credo democrático deweyano. Associamos a esse inventário nossa interpretação sobre a força significativa da democracia deweyana para a consecução de uma reflexão sobre os direitos humanos. Sob condições de vidas marcadas pela coerção, os direitos humanos não passam de meras concessões. No modo de vida democrático os direitos humanos estão resguardados desde o início, pois, neste modo de vida, as pessoas empreenderão continuamente um esforço moral de não se deixarem seduzir pelo poder que sujeita uns homens sobre os outros.
\end{abstract}

Palavras-chave: Democracia, direitos humanos, educação, inteligência, moral.

\section{THE WAY OF DEMOCRATIC LIFE AND ITS SOCIAL RESPONSIBILITY IN RELATION TO HUMAN RIGHTS}

ABSTRACT: This essay aims to discuss the relationship between democracy as a way of life and human rights. In this text we find an inventory of some of the

1. Rita de Cássia Pimenta de Araújo Campelo Doutora em Educação Escolar pela Universi dade Estadual Paulista/UNESP, Mestre em Educação pela Universidade Federal do Rio de Janei ro/UFRJ e Graduada em Filosofia pela Universidade Federal do Piauí/UFPI. Professora Adjunto A.II da Universidade Federal de Juiz de Fora/UFJF BRASIL.

2. Alexandre Lopes Campelo Mestre em Filosofia e Bacharel em Ciências Sociais pela Uni versidade Federal do Rio de Janeiro/UFRJ Pedagogo pela Universidade Federal do Piauí/UFPI. Professor de Fundamentos da Educação na UFPI BRASIL. 
main premises that explain the democratic creed of Dewey. We associate this inventory with our interpretation of the significant strength of Dewey's democracy to achieve a reflection on human rights. Under conditions of lives marked by coercion, human rights are no more than concessions. In the democratic way of life human rights are protected from the outset, for in this way of life people will continually undertake a moral effort not to allow themselves to be seduced by the power that subjects some men over others.

Keywords: Democracy, human rights, education, intelligence, moral.

Recibido: 28 de Junio de 2016 Aceptado: 21 de Septiembre de 2016

\section{Introduçao}

Os direitos humanos correspondem a certo estado da sociedade, isto é, ao modo como ela, ao longo do seu amadurecimento, conseguiu refletir suas prioridades. O pressuposto fundamental dos direitos humanos é o direito à vida (à existência, à integridade física e moral da pessoa e a não discriminação de todas as ordens). Esta é uma norma imperativa. Esta norma, aqui proposta, tem o sentido dado por Kant, que, ao que tudo indica, talvez por analogia, aproximou o termo mandamento, para indicar a fórmula que expressa uma norma da razão. Nicola Abbagnano (2000, p. 545), ao referir-se à norma da razão kantiana, diznos que ela é uma ordem, já que "a vontade humana não é a faculdade de escoIher apenas o que a razão reconhece como praticamente necessário, ou seja, como bom".

Desde o seu surgimento, a Declaração dos Direitos do Homem proporcionou um movimento do espírito que, ao mesmo tempo em que responde à necessidade elementar de proteção, no plano físico e moral, contra abusos de poder e contra às desigualdades das relações de força, abre um espaço para o debate contínuo dessa necessidade. Assim, diferentemente do que se pode imaginar, de modo apressado, é claro, o problema não está na inexistência de convenções acerca de direitos humanos, mas na necessidade de se dar contornos mais precisos aos direitos e obrigações, além de fazer funcionar os mecanismos para vigiar e reagir contra as violações criadas, principalmente, pelas políticas públicas que, ao invés de ampliarem de forma efetiva suas ações, produzindo uma consciência democrática, que viabilize a relação ação-reflexão-ação, apostam no assistencialismo e no conformismo dos sujeitos.

A elaboração dessa consciência democrática, a qual nos referimos, precisa considerar que a percepção dos direitos humanos está condicionada no espaço e no tempo, por múltiplos fatores de ordem histórica, política, econômica, social e cultural. Logo, seu real conteúdo está definido de modo diverso e suas 
modalidades de realização variarão, seja nos processos de violências, intolerâncias, guerras, fome, preconceitos, corrupções políticas, tráficos, disseminações de doenças, seja nos desenvolvimentos desenfreados, culturalizações, totalitarismos, exclusões.

Em vista de tal diversidade, reflexo da própria diversidade das sociedades e das concepções do homem, precisamos reconhecer que os direitos humanos são concedidos e garantidos pelos órgãos do Estado para promover o estabelecimento de condições humanas de vida, assim como o desenvolvimento multidimensional da pessoa. Sem a necessidade de rotulá-las dentro de segmentos grupais de qualquer ordem, porque tais rótulos acabam vilipendiando os direitos concretos do sujeito como pessoa.

Não é difícil percebermos a complexidade desse debate, e ele só é possível de ser constituído no âmbito democrático. É esse modo de vida, o democrático, que favorece, através das políticas públicas, um alargamento progressivo dos direitos humanos. Assim, além de um inventário dos valores que constituem uma sociedade, o povo e o Estado, na perspectiva aqui defendida, determinarão as práticas necessárias para a diminuição das desigualdades, de quase todas as ordens. Tal inventário de valores constitui uma das melhores maneiras de fluir a vida.

Falar dos direitos humanos, numa época em que eles são violados a todo instante, pode apresentar um caráter desafiador. Porém, o desafio maior é pensa-los no âmbito das políticas públicas. São essas políticas, voltadas para as necessidades dos cidadãos, que precisam, ainda, darem-se conta de que cada um tem direito à dignidade e ao respeito, a ser reconhecido como pessoa diante da lei e que ninguém, absolutamente ninguém, pode ser excluído das vantagens do direito e da justiça.

No Brasil, as políticas públicas, na sua maioria, reproduzem e reforçam o sistema de desigualdades predominante na sociedade. Infelizmente, quando essas políticas se mostram, o fazem através de aspectos predominantemente baseados no corporativismo e nos clientelismos. Essas modalidades de atuar politicamente são ainda as mais praticadas em nossa sociedade. Não é preciso ser nenhum grande especialista em política para perceber, dentro da própria vida comum, as mais diferentes atuações em nosso país de uso do corporativismo e do clientelismo. O homem comum confirma isto todos os dias nos seus mais imediatos modos de acessar o real: a televisão, os jornais, o rádio, a internet. Aqueles mais privilegiados de conhecimento acadêmico, como os cientistas sociais, estão, com certeza, e com toda a razão, cada vez mais perplexos com o avanço indiscriminado do corporativismo e do clientelismo.

Quando estudamos as discussões produzidas sobre direitos humanos, é firmada a noção de que os direitos civis, políticos, econômicos, sociais e culturais constituem um conjunto de valores essenciais para a manutenção da dignidade, da liberdade e do bem-estar dos homens. Essa noção é ampliada na medida que há a defesa de que tanto os direitos políticos, quanto os sociais, são elementos 
de uma sociedade na qual a liberdade política e a justiça social devem representar valores predominantes. Essa sociedade, a democrática, a qual nos referimos acima, deve, portanto, em suas políticas públicas, unir os anseios políticos e sociais de seu povo, garantindo o bem-estar real para uma vida verdadeira, concreta e possível.

Esse procedimento permitirá que essas políticas desenvolvam a sua real vocação: proteger o fraco, o vulnerável, considerando as exigências de solidariedade, respeito, ampliando a possibilidade de profundo desenvolvimento humano, onde a continuidade da vida humana seja prioridade, e não o desenvolvimento sem freios do poder de empresas, da indústria, dos militares, dos governos de poucos, dos pecuaristas, dos agricultores, dos acadêmicos, dos juristas, dos "ditos" empreendedores, dos traficantes, dos narcotraficantes, dos "especialistas da saúde", dos tecnólogos, enfim, dos mais diversos consumidores da vida humana sem escrúpulos, porque aprenderam que o importante é consumir sem precedentes e sem pensar na continuidade dos seus semelhantes, dos que não estão envolvidos no seu circuito de amizades.

Entretanto, enquanto a miséria, em todos os sentidos que essa palavra comporta, reinar, os direitos humanos constituirão ilusão. O desenvolvimento é, portanto, condição para uma realização cada vez mais completa dos direitos. $\mathrm{Na}$ verdade, o direito ao desenvolvimento humano, permitido pelas políticas públicas, e os direitos humanos não são contraditórios, ambos devem ser igualmente afirmados numa relação dialética entre o Estado e os indivíduos. Tal relação dialética poderá acontecer se os detentores dos poderes, que citamos acima, aceitarem as perdas necessárias para atingir-se o desenvolvimento humano, realmente humano, e não o desenvolvimento das suas individualidades, daquilo com que se preocupam. Daquilo com que lidam cotidianamente, é isto, certamente, um abandono irreparável daquilo que a estrutura escolar vigente deste país não tem preparado, aqueles portadores das benesses econômicas do mundo desenvolvido, aos moldes peculiares conhecidos por nós.

Dissemos anteriormente que o debate sobre direitos humanos e políticas públicas está permeado pela complexidade da constituição de um modo de vida, o democrático. Inicialmente, não é nas ideologias nem no Estado C, mas nas consciências populares que devemos buscar os princípios efetivos das políticas públicas. É no reconhecimento das diversas experiências vividas que encontramos as expressões da necessidade de criar homens livres, que sejam capazes de entender suas carências. Conscientizados de suas carências, as massas humanas serão capazes de estabelecer as resistências necessárias para garantir um modo de vida democrático e não mais aceitarem viverem sob o panóptico que são submetidas, ao longo de suas duras vidas de sofrimento, escravidão, exclusão e a mais completa paralisia frente às manobras do Estado e da política "macabra" vigente em nossa cidadania invertida. 
É preciso estabelecer uma diferença entre cidadania e massa. A massa é governada, a cidadania se autogoverna. Cada vez mais estamos sendo inseridos numa sociedade de massas, governados por dispositivos de indução de condutas, formatação de subjetividades, fabricação de desejos, estimulação permanente de uma liberdade conduzida, monitorados por controles externos sobre os quais não temos controle, intimados a querer o que os outros planejaram que desejemos como bom para nós. Desta forma, a liberdade se confunde com o desejo dos outros, e nossa ação individual é sujeitada às estratégias de governo dos outros. Estes seriam os parâmetros de uma sociedade que nos transforma em massa de manobra, massa de consumidores, massa de trabalhadores, massa de contribuintes, massa de moradores. Massificados somos melhor conduzidos. A sociedade de massa convive com uma democracia forma, ou democracia de mínimos, sendo sua negação constante. Vale lembrar aqui que Guy Debord nos mostrou isto, brilhantemente, em sua obra a Sociedade do Espetáculo.

Defendemos que a efetiva abordagem dos direitos humanos, no âmbito das políticas públicas, tal como foram aqui caracterizadas, só se realiza na democracia. A democracia surge, portanto, como o fundamento básico para a realização dos direitos humanos e das políticas que os garantam. A democracia, encarada como um modo de vida, conforme foi defendida por John Dewey no seu Democracia e Educação (1916), como vida compartilhada, em constante debate, no qual sejamos capazes de identificar nossas diferenças e necessidades, permitenos a exigência da justiça social. Essa justiça social é cara, necessita de resistência, não acontece sem luta, carece de reflexão constante e cotidiana, não valoriza a vida técnica, dirimi os preconceitos, exclui as certezas, valoriza o pensamento reflexivo, a inteligência, a cooperação, a co-participação.

Neste contexto, entendemos que a questão que nos mobiliza ganha ênfase, pois estamos argumentando que a massa dilui o conceito de povo, transformando a cidadania num mero conceito formal, sem uma efetiva preocupação por sua formação. A cidadania, como a democracia, tem por base a constituição da autonomia que, por sua vez, parte do princípio de que deve ser apreendida como exercício virtuoso da ação. Sem a práxis não há autonomia. Um novo sentido da liberdade se abre. Não nascemos sabendo ser livres. Temos que aprender a viver como pessoas livres.

Neste ponto, na construção da subjetividade virtuosa, aprendemos, criticamente, a ser livres. Assim, é imprescindível repensar o sentido da democracia a partir da alteridade, do outro como referência ético-política do bem e da justiça. A democracia não tem por base o interesse egoísta, mas o bem comum, o bem de todos. Perspectiva que, para alguns, é conceituada como idealismo (às vezes até dito como idealismo infundado), mas é aí que se encontra o problema: pensarmos que o bem de todos é idealismo e não vida normal, normalidade do mundo, fim último de humanidade. 
Viver nas sociedades não democráticas não é uma atividade normal, mas é algo que dependente de um pagamento, de uma obrigação dramática de trabaIhar até o último limite das forças, e isso deve ser aplicado à grande maioria de todas as pessoas existentes. Todavia, alguns poucos não precisam sofrer este tratamento, pois nasceram para comandar, distantes das massas e de seus trabaIhos práticos e sem valor, absortos no ócio que lhes é próprio e dado naturalmente. Esta é a democracia egoísta, não é essa que devemos aprender, mas aquela que resguarda o bem de todos.

A pergunta que podemos fazer agora é: onde aprendemos a pensar a democracia tal como a defendemos neste ensaio? Onde podemos pensar a democracia como um esforço moral constante para o diálogo, que nos instrumentaliza para a construção de uma consciência social exigente a respeito dos direitos humanos?

O espaço é, sem dúvida, a escola. É lá que podemos aprender que a cidadania é, eminentemente, social. O governo e suas prioridades, dentre elas suas políticas públicas, são reflexos daquela consciência exigente que, tendo conhecimento de seus direitos, amadurece suas necessidades, suas prioridades que serão supridas na esfera democrática. Aprenderão a resistir, a lutar, a refletir, a se posicionar frente às distâncias que os pequenos grupos criam como naturais e, na medida que tomarem posição, possam transmutar as distâncias rumo à democracia.

Precisamos enfatizar que não há simplicidade em tudo isso que acabamos de defender. Esse movimento, que constrói um olhar crítico frente às nossas necessidades mais fundamentais, é fruto do empenho constante das pessoas, mas elas precisam ser ensinadas a se reconhecerem na práxis comunitária.

Esse movimento, considerado por alguns antiquado ou fruto da revolta sem fundamento, principalmente por aqueles que têm voz nas deliberações políticas e sociais, precisa, urgentemente, ser revisto pela educação, precisa ser retomado no cotidiano da nossa educação, para que possamos, então, pensar, debater e exigir das políticas públicas, especificamente aquelas que dizem respeito aos direitos humanos, sua ampla e constante efetivação, caso contrário, essas políticas continuarão a desdenhar da história, de uma utopia benfazeja que sustenta o sonho democrático, que nasce com uma fé, aquela que crê no homem comum e em sua inteligência.

\section{A fé na democracia e os direitos humanos}

Até aqui argumentamos a favor de uma ativa relação entre os direitos humanos e um tipo de democracia, aquela compreendida como um modo de vida. Que tarefa está à nossa frente? Criar esse modo de vida que, tal como foi refletida por John Dewey, principalmente, no seu Democracia e Educação (1916), apoiarse-á em uma imaginação política e no espírito criador do homem comum. 
No Brasil e no mundo se configura, hoje, como um enorme desafio, tendo em vista as condições críticas e complexas que nos habitam, construir uma sociedade verdadeiramente democrática. Quando imaginamos que ela já existe, será um equívoco pensarmos que ela se perpetua automaticamente.

Esta reflexão nos sugere que a criação de uma sociedade democrática exige esforço contínuo para a sua manutenção, reavaliação. Entretanto, habituamo-nos a pensar na democracia como num "maquinismo político". Esta expressão deweyana nos revela que há um tipo de democracia cujo funcionamento exige que os cidadãos se mostrem razoavelmente sinceros em desempenhar seus deveres políticos. Porém, contrariando essa submissão social, a democracia, na visão do filósofo estadunidense, é um modo de viver, significa dizer que, inicialmente, ela se constitui pessoalmente, norteada pela confiança, pela fé nas possibilidades da natureza humana. Em seguida ela ganha corpo e pleno alcance humano quando, continuamente, é ativamente elaborada na comunidade humana.

Dewey (apud EDMAN, 1960, p.330) é enfático: "A fé no Homem Comum é um dogma do credo democrático", que pode até ser estabelecida em estatutos, por exemplo, mas, para se efetivar, precisa ser posta em ação continuamente entres os seres humanos. Essa fé democrática na igualdade humana se sustenta na crença de que cada indivíduo tem direito a igual oportunidades para se desenvolver, dirigindo sua própria vida, livre de qualquer tipo de coerção, desde que lhes sejam propiciadas condições justas de vida.

Ter fé na natureza humana significa crermos na capacidade da inteligência do homem comum para pôr-se no livre jogo das ideias e dos fatos, assegurados por um ambiente que não rejeite a livre investigação, a livre reunião e a livre comunicação, que confirmam o papel da reflexão, da persuasão, da discussão, ações estas que cooperam na formação da opinião pública que, ao constituir-se considerando esses exercícios democráticos, é capaz de, continuamente, autocorrigir-se. Inteligência, portanto, implica, na visão deweyana, ação em relação à existência social, no sentido de zelar por sua contínua renovação. Logo, somos levados a considerar que há uma inteligência que é social.

Essa inteligência opera sobre o mundo para torná-lo um lugar mais razoável, defende Dewey em seu Logic. Conforme Allport (1989, p. 277), o pensamento em Dewey "é sempre mente em uso"; não se trata de imagens ou estados mentais, mas de "uma procura bastante ativa de significados coerentes e úteis para a atividade prática. O pensamento é um instrumento virtual equiparado com a inteligência. Ambos são os meios pelos quais antevemos o futuro, dando ordem e direção às nossas ações".

Para Dewey, conforme argumenta Shook (2002), a democracia tem como características a sensibilidade a conflitos sociais e a valorização da investigação pública dos modos de resolver conflitos. Em uma democracia, compreendida como um modo de vida, as pessoas que experimentam os problemas sociais devem participar da investigação das possíveis soluções, além de decidirem se 
os experimentos que possivelmente solucionarão os problemas são eficazes. Assim, no modo de vida democrático, os valores sociais são sempre provisórios e falíveis, além de residirem nas experiências sociais das pessoas.

O Homem Comum, Dewey o vê nas reuniões dos vizinhos, nas esquinas, nas salas, nas casas, trocando ideias, com plena liberdade de pensamento e expressão, falando a favor ou contra as notícias, sem se deixar conduzir pela intolerância, ódio, insultos de quaisquer tipos diante das possíveis divergências. O que solapa a forma democrática de viver é exatamente qualquer impedimento à plena comunicação entre os homens, além de uma mentalidade forjada na suspeita mútua, no medo, no abuso, no ódio, no preconceito de qualquer ordem.

A democracia deweyana se sustenta no trabalho pessoal, que necessita do coletivo para ser realizado e, mesmo havendo objetivos diferentes neste coletivo, é preciso se ter a consciência de se construir o hábito da cooperação amigável. Os conflitos e embates não estão afastados da fé que devemos ter na democracia, eles servem como entendimentos cooperadores, permitindo aos sujeitos envolvidos nas controvérsias possibilidade de se expressarem, sem que nem um nem o outro queiram dominar, ridicularizar, insultar, intimidar seu interlocutor.

Ouvir o outro em uma discussão, além de lhe dar a oportunidade de externar suas ideias, manifestando uma opinião contrária não é só um direito que esse outro tem, mas, além disso, garante aos debatedores o enriquecimento de suas experiências pessoais. Essas atitudes são inerentes ao modo de viver democrático.

Ao defender este modo de crer e expressar sua fé democrática, Dewey pode ser acusado de extrair seus argumentos de lugares-comuns, particularmente aqueles vinculados ao caráter moral de suas premissas, entretanto, segundo ele, não há outra maneira de apresentá-las. Portanto, quando Dewey recorre a uma noção de fé, seu sentido não está vinculado a ideais estáveis, obscuros ou sobrenaturais, mas, sim, como diz em Uma Fé Comum, esta fé tem a ver com uma emancipação da qualidade religiosa. A fé emancipa-se de um caráter sobrenatural e direciona-se para uma crença nos ideias de ordem social.

A objeção ao sobrenatural explica-se pela obstrução que ele provoca acerca das relações naturais entre os homens, impedindo que em relação a elas sejam construídas estratégias para avaliá-las e modificá-las. Rejeitar, portanto, o sobrenatural significa renunciar a qualquer tipo de divisão (os bons dos maus, os justos dos pecadores, os eleitos da massa), tão comum em muitas religiões. Contudo, isto não significa que dessas relações não resulte um progresso espiritual, desde que ele advenha da reflexão "dos valores que fazem parte das verdadeiras relações dos seres humanos entre si" (DEWEY apud EDMAN, 1960, p. 320).

Para a fé democrática deweyana, "Se somos ou não irmãos em qualquer sentido metafórico, pelo menos estamos todos juntos no mesmo barco, atravessando o mesmo oceano agitado. A importância religiosa desse fato é infinita" (DEWEY apud EDMAN, 1960, p. 323). A fé de Dewey na democracia, é, tal como enxergou Shook (2002, p. 169), "uma confiança, na curiosidade e coragem do homem". 
O valor da fé democrática está no seu caráter social. "Não fica bem àqueles que afirmam ser a fé capaz de remover montanhas negar a possibilidade de sua manifestação em realidades palpáveis". Para Dewey, é menos promissor tomar como objetivo da fé o aspecto sobrenatural.

Defender o caráter moral acerca de sua noção de democracia significa confirmar que ela é um meio de vida pessoal, "um ideal moral que, ao tornar-se um fato, se torna um fato moral", "um lugar-comum dentro da vida" (DEWEY apud EDMAN, 1960, p. 333) e não algo institucional, externo. Precisamos nos habituar a tratar a democracia como um meio de vida pessoal.

A argumentação deweyana acerca da democracia expressa sua posição filosófica que rejeita experiências de submissão a alguma forma externa de controle, a alguma autoridade. A democracia, como um modo de vida, constitui-se a partir da confiança na experiência humana, que cria objetivos e métodos que tornam essa experiência mais rica. É o processo dessa experiência que é mais importante. Experiência, para Dewey, diz respeito ao livre intercâmbio dos indivíduos com o ambiente humano, desde que lhes permita melhorar e aumentar o conhecimento das coisas. É este intercâmbio, tal como foi caracterizado, que possibilita a comunicação e a co-participação, condições essências para o modo de viver democrático. Sem essas condições, o que há é a submissão de alguns a opiniões pessoais de outros. "Uma vez que o processo da experiência pode ser educativo, a fé na democracia é a própria fé na experiência e na educação" (DEWEY apud EDMAN, 1960, p. 334).

Para Dewey, no modo de vida democrático os contatos, intercâmbios e as comunicações não são limitados e devem ser contínuos. São essas ações que ampliam e enriquecem as experiências humanas, onde todos contribuem e participam.

Hoje, ao defendermos uma reflexão sobre os direitos humanos, vinculando-os a um modo de vida democrático, tal tarefa nos obriga a reconhecer que a possibilidade de sua defesa acontece graças ao enfretamento, sofrimentos e luta da comunidade humana de que somos parte. Se assim o é, temos a responsabilidade de transmitir os valores que nos permitirá desejar, fundamentalmente, que as gerações futuras não deixem de preservar o desejo da dignidade humana, com a intenção e o trabalho de solidifica-la. Reside aqui um valor social que nos coloca dentro da comunidade humana, carregando o valor de uma fé que não se limita a uma seita ou classe social. "Tal fé sempre foi implicitamente a fé comum da humanidade. Falta torna-la explícita e militante" (DEWEY apud EDMAN, 1960, p. 326).

Quais são as perguntas que o mundo atual nos lança acerca dos direitos humanos? Ao nosso ver, a principal delas é a seguinte: Como incorporar a profunda necessidade de realização dos direitos humanos, considerando-os como base moral para a democracia? 
O panorama do mundo atual nos revela que o anseio pela "democracia" muito mais está relacionado à submissão dos mais fracos às ideologias econômicas e políticas dos mais fortes. Sendo assim, as democracias existentes só podem ser consideradas democráticas no nome, visto que ainda se sustentam na escravidão das consciências, na heteronomia, na conformação, no domínio de umas nações sobre as outras. Revela-se, portanto, que democracia funciona como um slogan, assim como a ideia de cidadania, paz, liberdade, autonomia, justiça e a própria ideia de direitos humanos. Aqueles que se beneficiam de uma ideologia democrática, recorrem a estes conceitos, porque eles justificam e cabem em qualquer discurso que os utiliza como base moral para os seus empreendimentos financeiros e políticos. Entretanto, quando buscamos suas reais feições morais, deparamo-nos com a palidez de sua existência verdadeiramente humana no mundo real.

Diferente do que encontramos hoje, não encerra em tolice cremos e desejarmos que as instituições políticas devam existir para refletir e agir tendo como fim a dignidade humana e que o critério de nossas ações artísticas, científicas, sociais, econômicas, religiosas, educacionais é a constituição de uma moral, cujo substrato, alicerce deva ser a dignidade humana. Não é fácil alimentarmos este ideal, mas para compreendê-lo, de fato, precisamos saber o que entendemos ou o que entendem aqueles que defendem o valor da democracia.

É sabido que as situações econômicas agem como forças controladoras das relações humanas. Porém, a democracia não pode ser tomada como subproduto dessas relações. Em seu texto Aplicações da liberdade humana é esclarecedora a perspectiva deweyana de que a moralidade deva ser o principal regulador dos deveres sociais e que a cooperação, que faz parte do ideal democrático, atravesse todos os elementos constituidores de nossa humanidade. Cremos, portanto, que os direitos humanos, considerando o que investigamos até aqui, na democracia, entendendo-a como modo de vida, não são meras concessões, ao contrário, são eles que viabilizam esse modo de vida.

Mais acima ressaltamos a importância que Dewey deu à inteligência humana, quando esta se inclina a considerar seriamente os problemas sociais. No início deste artigo inventariamos uma série de mazelas que lançam uma parte gigantesca da humanidade num abismo cavado pela ganância de grupos de pessoas forjados na ideia de que o medo sustentará seus planos de ação autoritários, totalitários e os manterão onde sempre estiveram, nos postos de comando, empenhados, portanto, em confirmar a ideologia de que o amor ao poder controla a atividade humana, constituindo razão suficiente para que não aja nenhum empenho para um rigoroso e sério trabalho a favor dos direitos humanos.

Como, então, reagir a essas forças que, opondo-se a uma atitude reflexiva, preferem o ódio?

A resposta deweyana está na sua crença em um tipo de educação que, desde cedo, crie micro-comunidades democráticas, orientadas pela inteligência social, 
para preservar e ampliar experiências compartilhadas de cooperação diante de dificuldades e conflitos. Shook (2002) nos lembra que Dewey se preocupa em afirmar que sua concepção de democracia deve atingir todas as formas de associação humana, desde a família, passando pela escola, indústria e religião. Metaforicamente, na leitura de Shook (200, p. 171), a educação "é a máquina mais fundamental da democracia", e, citando Dewey, complementa: "através da educação, a sociedade pode formular seus próprios objetivos, pode organizar seus próprios meios e recursos, e assim configurar-se definitiva e economicamente na direção que desejar seguir" (DEWEY apud SHOOK, 2002, p. 171).

Na sociedade pensada por Dewey não há espaço para outro comportamento, outro ideal, outra moral que não estejam alicerçados na atitude democrática, visto que é ela que libera as capacidades de resolução dos conflitos, na medida em que enseja o exercício de trabalhadores, empregados, professores, estudantes, etc. a investigarem, de modo inteligente e experimental suas realidades, avaliando, reavaliando e ajustando suas experiências sociais. Por esta razão, "A filosofia social de Dewey é uma filosofia da democracia e, como tal, deve ser uma filosofia da educação" (SHOOK, 2002, p. 172).

\section{Democracia, educação e responsabilidade social}

É para a esfera social que devemos olhar quando estamos preocupados com os direitos humanos, assumindo o posicionamento de que eles têm como objetivo o bem social. O fundamento moral para refletirmos sobre os direitos humanos devemos apanhá-lo no mundo social, logo, os direitos, em uma democracia, não têm sua origem e suas justificativas em realidades transociais.

A primazia de nossas investigações não deve estar fora das conexões sociais que, no modo de vida democrático, exigem efetiva responsabilidade social. Quanto a isto, Shook (2002, p. 180) argumenta que, para Dewey, "as responsabilidades são a manifestação de uma cooperação grupal com vistas à produção de bens. A cooperação produz os bens mais valiosos da existência". Acrescentamos que a referida produção de bens precisa ter como fundamento o critério moral da dignidade humana, o respeito irrestrito à humanidade, opondo-se a qualquer tipo de violência ou brutalidade.

A filosofia social deweyana, baseada no comunitarismo, explica sua filosofia da democracia. Podemos aqui sugerir que sua visão de comunidade democrática não dispensa seu compromisso em relação aos direitos humanos. Atento a investigar a relação da democracia com a responsabilidade e a justiça no pensamento deweyano, Shook (2002, p. 185) diz o seguinte:

Dewey sugere um modelo unificado de democracia, pois sua compreensão da verdadeira democracia exige que o respeito pela dignidade e autonomia, juntamente com uma sincera preocupação para com o bemestar de todos, seja reconhecido por toda a comunidade como essencial e 
fundamental para o funcionamento apropriado da cooperação social e da responsabilidade moral.

São exatamente as características que constituem esse modo de proceder da comunidade democrática, que nos leva a dizer que ela se comporta preocupada em considerar diuturnamente os direitos dos humanos não como abstrações, mas, sim, como motivações sociais que alocam as pessoas na comunidade humana. Em The Philosopher of the Common man, de 1940, comemorando seu octogésimo aniversário, Dewey rejeita qualquer pretensão intelectualista, ao explicar que sua crença na correlação defendida por ele entre pensamento, educação e inteligência que, como vimos até aqui, são os edificadores e guardiães da comunidade democrática, alimentada pela fé democrática, não foi sua invenção, diz ele: "Adquiri-a no meu ambiente que sempre esteve sob a influência do espírito democrático" (DEWEY apud EDMAN, 1960, p. 331).

Acreditamos que até já nos é possível afirmar que numa sociedade democrática as pessoas não se esquivam de refletir sobre suas responsabilidades sociais. Esta é uma atividade levada a sério, pois entende que viver em comunidade traz a compreensão de que o bem social exige contínuos ajustes, visto que as realidades humanas se modificam. Tendo em vista este necessário esforço moral, que nos incumbe de resistirmos ao falso conforto dos dogmatismos e empreendermos uma atitude muito mais ativa, reflexiva, logo, muito mais trabalhosa, colocando-nos em estado de contínua prontidão para o debate, é que o papel da educação é tão central no modo de vida democrático.

A educação, para a democracia, tem a função de preparar pessoas empenhadas em reconhecer a contínua mutação da realidade, não reconhecendo nisso nenhum empecilho social para continuarem vivendo juntas. Pensar assim é tarefa para a vida toda e se constitui num golpe a uma concepção de perfeição, que afasta todos os problemas de conduta humana.

Como mostramos anteriormente, a democracia não é um maquinismo político a partir do qual as pessoas se submeteriam ininteligentemente. Ao contrário, na democracia como modo de vida, as pessoas precisam exercitar, esforçarem-se incondicionalmente, trabalhar em conjunto "na supervisão e ajuste de papéis e deveres sociais, a avaliação e aperfeiçoamento da responsabilidade será uma tarefa social" (SHOOK, 2002, p. 187) que pode ser experienciada na escola. Assim, a educação não é só uma instituição, ela é uma atividade essencial para a democracia, visto que Dewey considera a educação uma atividade moral que alerta, continuamente, as pessoas a se conduzirem de modo socialmente responsável, inteligente, diante dos desafios sociais, que são sempre plurais.

Investigando o Democracia e Educação, Pimenta (2008) destaca que, para Dewey (1959, p. 204), a sabedoria jamais se desconectou da orientação da vida. "Somente em educação, e nunca na vida do agricultor, do marinheiro, do negociante, do médico ou pesquisador de laboratório, saber significa primaria- 
mente um lastro de informações separadas da ação". Por isso, a educação precisa construir um acervo de conhecimentos sociais.

Portanto, Dewey (1959, p. 211) vê como fundamental "que a educação (especialmente em todas as suas fases que não sejam as mais especializadas) adote para essa seleção o critério do valor social". Defende ainda que o currículo "deve tomar em conta a adaptação dos estudos às necessidades da vida atual em sociedade"; sendo que "a escolha deve ser realizada com o fito de melhorar a vida que levamos em comum, de modo que o futuro seja melhor que o passado" ${ }^{\prime 3}$. As coisas essenciais em educação dizem respeito às socialmente mais fundamentais: "Existe verdade no dizer-se que a educação deve primeiro ser humana e só depois profissional".

Por esta via, Dewey (1959, p. 317) enfatiza que "Estudo humano é todo aquele feito de modo a aumentar o interesse pelos valores da vida; é todo estudo que acarrete maior sensibilidade em relação ao bem-estar social e maior aptidão para promover esse bem-estar". Articulando um discurso que nos parece o posicionamento mais contundente, vivo, e integrado ao seu projeto democrático, o seguinte trecho de Dewey permite a devida compreensão da visão política e do equilíbrio de seu pensamento a respeito da educação. Trata-se de um excerto significativo, no conjunto dos escritos do filósofo, que traz a sua visão acerca do que é o humano:

Mas os que assim se exprimem têm frequentemente no espírito, ao proferir a palavra humano, só uma classe altamente especializada: a dos homens instruídos que conservam as tradições clássicas do passado. Eles se esquecem de que a matéria se humaniza na proporção em que se relaciona com os interesses comuns dos homens, em sua qualidade de homens.

A conservação das sociedades democráticas depende, particularmente, do costume de organizar-se um curso de estudos de critério largamente humano. A democracia não pode florescer quando os principais critérios para a escolha das matérias educativas são os fins utilitários estreitamente concebidos para as massas, e, quando se escolhem para a instrução mais elevada dos outros poucos, as tradições de uma classe instruída especializada. A noção de que os elementos essenciais da educação elementar são os três R (ler, escrever e contar) ${ }^{4}$, esteiase na ignorância das coisas essenciais requeridas para a realização dos ideais democráticos. Presume-se, assim, inconscientemente, serem irrealizáveis estes

3. Para Dewey (1959, p. 274), "considerar o currículo em seu conjunto como uma espécie de agregado formado pela justaposição de valores isolados, é o resultado do isolamento dos grupos e classes sociais". Por isso, a educação tem como tarefa "lutar contra esta segregação, para que os vários interesses possam mutuamente reforçar se e influenciar se".

4. Os tradutores do livro observam, em nota, que os três $\mathrm{R}$ se referem a reading, writing e reckoning. 
ideais; presume-se que no futuro, assim como no passado, terem "um meio de vida" deve significar, para a maioria dos homens e mulheres, fazer coisas não importantes, nem livremente escolhidas, ou nobilitantes para aqueles que as fazem; coisas que obedecem a fins desconhecidos para aqueles que as fazem e que são executadas sob a direção de outras pessoas, tendo-se em vista uma recompensa pecuniária. Para a preparação de grande número de indivíduos para essa espécie de vida, e só com este intuito, é que é essencial a eficiência maquinal no ler, escrever e contar, juntamente com a obtenção de certa destreza muscular. Tais condições também eivam de iliberalidade a educação denominada liberal (DEWEY, 1959, p. 212).

A educação que partilha de responsabilidades sociais precisa apresentar situações cujos problemas sejam relevantes para a vida em sociedade. Para Dewey, portanto, é artificial a separação entre a vida social e a escola.

A educação, tal como vimos até aqui, tem como tarefa primeira insistir que "Cada membro de uma democracia compartilha a responsabilidade no progresso das causas da democracia: igualdade, dignidade e autonomia" (SHOOK, 2002, p. 188). Além disso, é pela educação democrática que se aprende ativamente que a coação deve ser combatida, constituindo-se a escola num espaço cujo clima intelectual, cultural e social concorda que a violência é uma força ininteligente. No modo de vida democrático e na educação que ele cria, todo são moralmente responsáveis.

\section{Considerações finais}

Utopia, projeto incompleto, não resta dúvidas de que não é tarefa fácil a realização de um modo de vida como aquele desejado por Dewey. Ao nosso ver, no entanto, a referida dificuldade se apresenta porque ela se revela como uma concepção social extremamente refinada a respeito do modo como as pessoas podem vir a existir, porque exige que as pessoas deixem de lado suas pretensões egoístas, logo, o trabalho deve ser constante e ininterrupto.

A sofisticação do projeto democrático reside no fato de que ele exige um esforço moral contínuo e cuidadoso das pessoas para que, como dissemos anteriormente, os direitos humanos não sejam tratados como concessões dos mais fortes para os mais fracos, ao contrário, no modo de vida democrático, ele só se viabilizará se sua constituição começar pela justiça social. Em sociedades não democráticas a movimentação social que as políticas autoritárias ensejam, recorrentemente, isola as pessoas em grupos, impossibilitando a honesta comunicação entre esses grupos. Na democracia, é a comunicação que compartilha os sentimentos e as ideias que nela se efetuam.

Em The Public and its Problems, Dewey se manifesta acerca da democracia afirmando que ela deve começar em casa, considerando que nossa casa pode ser uma comunidade bem harmonizada. O ajustamento harmonioso é uma 
conquista que se dá pelo intercâmbio de atividades na comunidade que, na democracia, deve ser permanente. Este esforço tem um objetivo que é caro à humanidade: a busca da felicidade. O direito à busca da felicidade é o direito humano mais fundamental. Todo ser humano deveria ter o direito de viver livre de coações, impostas por quem quer que seja.

Contudo, se vivemos sob uma ordem econômica que não se reconhece como imoral ao tratar como natural a fome de milhares frente a abastança de poucos, a indignidade do desemprego, da ausência de saúde, a plena tecnificação da educação em prol de uma formação única e exclusivamente para o trabalho repetitivo, estamos longe de compreender o modo de vida democrático deweyano. Ele, como vimos ao longo deste ensaio, alimenta-se de uma fonte que não é nem técnica, muito menos material, mas é moral, porque se baseia na fé, na capacidade que os seres humanos têm de conquistar a liberdade acompanhada do respeito às pessoas.

\section{Referências Bibliográficas}

ABBAGNANO, Nicola. Dicionário de filosofia. $4^{\text {a }}$ ed. São Paulo: Martins Fontes, 2000.

ALLPORT, Gordon W. Dewey's individual and social psychology. En SCHILPP, Paul Arthur; HAHN, Lewis Edwin (orgs.). The philosophy of John Dewey. The Library of Living Philosophers, vol. 1. 3. ed. Carbondale: Southern Illinois University, 1989.

DEWEY, John. Democracia e educação: introdução à filosofia da educação. Tradução Godofredo Rangel e Anísio Teixeira. 3. ed. São Paulo: Nacional, 1959.

DEWEY, John. Logic: the theory of inquiry. Nova York: Henry Holt, 1938.

EDMAN, Irwin. John Dewey: sua contribuição para a tradição americana. Tradução Stella C. L. Tostes. Rio de Janeiro: Fundo de Cultura, 1960.

DEBORD, Guy. A Sociedade do Espetáculo. Tradução Estela dos Santos Abreu. Rio de Janeiro: Contraponto, 1997.

PIMENTA, Rita. [Rita de Cássia Pimenta de Araújo]. Lógica, investigação e democracia no discurso educacional de John Dewey. 2008. 180 f. Tese (Doutorado em Educação). Universidade Estadual Paulista "Júlio de Mesquita Filho", Faculdade de Ciência e Letras,Campus de Araraquara, SP, 2008.

SHOOK, John R. Os pioneiros do pragmatismo americano. Tradução Fábio M.

Said. Rio de Janeiro: DP\&A, 2002. 